\title{
Research on the Strategy of Cultivating Enterprise Service Climate
}

\section{Dong YUAN ${ }^{1}$, Nian-Bai $\mathrm{LI}^{1}$, Yong-Jun DUAN ${ }^{1}$, Han-Song $\mathrm{CHEN}^{2}$, Wei YU ${ }^{2, a}$,*}

1. Shandong weifang tobacco company, P R China.

2. Shandong University of Finance and Economics, P R China.

aemail:longkouyuwei@sina.com

*Corresponding author

\section{Keywords: Service Climate, authorization, training}

\begin{abstract}
Service intangibility and interactive means service product performance standards vary from person to person, so the service innovation must be is to take the "prior" in a controlled manner. Managers should cultivate service climate by training system, internal competition mechanism, authorization system, information channels and so on.

A large number of theoretical researches and management practice of enterprises have proved that service climate can enhance staffs' skills and emotion, establish the consciousness of service and stimulate organizational citizenship behavior, so as to improve customer perceived service quality and their satisfaction. Different from the manufacturing technology, the service product is provided instantly, the staffs' performance in the "truth moment" directly determines the customer's satisfaction. So it is difficult to monitor and evaluate the service in "truth moment". Service atmosphere can replace the monitoring of the management for staff's service behavior. Strong service climate of enterprises can provide employees with the freedom and resource to encourage staffs to implement service innovation. For employees, the service enterprise service climate is more strong, the more likely to inspire a sense of service oriented and to seek a better solution for customers' problems. In addition, service products need customers to participate in the service, the service climate of the enterprise will have an impact on the customer's perception and regulate the customer's mind, then affect the evaluation of the service. Therefore, service companies must create service climate, promote service innovation and corporate brand building by the service climate.
\end{abstract}

\section{The Connotation of Service Climate}

Since the study of Schneider, scholars have made a lot of research on the connotation of service climate. According to Schneider's understanding, the climate of the service is the employees' view on the organizational requirements, support services, service behavior of policies, practices and procedures. In other words, service climate is employees' perception of organizational emphasis on service and service innovation. According to social exchange theory, when employees perceive that the organization attach importance to service innovation, they are willing to invest resources even at the expense of profit temporarily, and innovation orientation will be within the scope of the organization to facilitate the emergence of innovative behavior.

On the basis of deep mining of service innovation and innovation measurement, Schneider and others have worked out the service climate scale, which includes the organization of customer orientation, management measures and customer feedback. Lytle discussed service climate from servant leadership, empowerment, training recovery and so on, which outline the antecedents of service innovation

Good service environment will have a significant impact on service enterprise performance through the perception of employees and customers. Good organizational service climate will optimize the internal environment of the service innovation and enhance recognition of the high quality of service. Customer service climate will enhance cognitive of service enterprises by a subtle way, also has greater tolerance on service failure, and then improve overall cognition of the service quality of enterprise. 


\section{Factors Affecting the Service Climate}

According to the description of the Reiter, ten factors can influent the service climate. They are (1) the servant leadership which refers to the enterprise leadership act as an example of quality service for employees. (2) service vision which refers to the enterprise leadership believes in the service oriented enterprise vision. (3) companies dealing with the customer which refers to the enterprise satisfy the customers' demand and improve customers' satisfaction. (4)authorized which refers to the enterprise grant employees the responsibility and power to meet customers' needs. (5) training which refers to the enterprise improve the service quality of the staff through all kinds of training work. (6) Award which refers to the enterprise recognition and reward employees' service behavior. (7) to prevent the service error which refers to the enterprise take various measures to prevent service errors. (8) remedial measures which refers to the various enterprises take effective measures to deal with customers' complaints. (9) service technology which refers to the enterprise use high-tech equipment and systems for customer service. (10) quality standard which refers to the enterprise use the internal communication activities to make employees understand the enterprise service quality standards.

\section{Individual Behavior of Manager}

According to the theory of service profit chain, employees' behavior to customer is closely related to the internal management. Therefore, the service enterprise managers should show the appropriate behavior to create service climate. These acts include the delivery of service values to employees, designated service oriented policies and incentives to control the performance of staff services, etc. From the employee's perspective, leadership behavior can be on behalf of the enterprise whole development idea and direction, managers act as example, it be possible to stimulate the employee innovative behavior.

\section{Internal Management Processes and Systems}

Leadership behavior focuses on the performance of managers, enterprise internal management process system is the internal standardization and institutionalization of the enterprise performance. Enterprise internal management processes and systems, including employee participation in management system, incentive system, information transmission system and training system, the system will have a great impact on corporate resources and employees' mental, thereby affect the service innovation climate.

\section{The Openness of Corporate Culture}

The enterprise climate which is beneficial to the service innovation must be open and orderly. The construction of service climate requires enterprises integrate external information and resources in an open perspective, and solidify through the organization of learning, and then become the source of enterprise's core competitiveness. Open culture need organization make adjustments to increase strategic flexible elements, and strengthen the enterprises ability to deal with the uncertain risk, increase enterprise intangible resources reserves by way of strategic alliance and learning alliance.

\section{Service Climate Construction Strategy based on Innovation}

\section{Enhance the Organizational Support of Employees in Service Enterprises}

Organizational support of employees in service enterprises is the main factor influencing the job involvement of employees. Organizational support can effectively improve employee's organizational commitment, loyalty, enthusiasm and creativity in the work, deal with in a variety of problems encountered in service aimed at customer satisfaction. Perceived organizational support is the overall perception of the organization of various software and hardware elements, Measures for enterprises to enhance employees perceived organizational support includes improving their working, living and learning environment, improving the internal hardware background, establishing the mechanism to collect opinions and suggestions of employees, ensuring the employees of 
communication channels, attracting employees to participate in enterprise strategic planning and development, reflecting staffs' reasonable opinion for enterprise management, reducing the information asymmetry between the information gap and information exchange, paying attention to informal channels, sorting out solutions to employees through informal channels to reflect the problems of leaders, trying to establish a good personal relationship with employees, expanding the scope of management, appropriately sealing with staffs' work- family conflicts.

\section{To Empower Employees and Broaden the Channels for Employees to Participate in Management}

In accordance with the principles of power and knowledge matching in the knowledge management, the power within the service enterprise should be inclined to the employees. Because staff is on the front line of the customer service, they master a large number of customers' demand information. Compared with the manager, they are also more understanding of customer service quality assessment and satisfaction. Enterprise employees participate in management can greatly mobilize the enthusiasm, and form a strong service climates. It should be explained that the authority including systematically authorization and special authorization. Systematically authorization refers to take the authorization into the enterprise system and the daily work to form a delegation of authority. Special authorization is a pointer to a specific time and specific events. Two authorized methods shall be adopted by the enterprise customer at the same time, allow employees to remedial services using the duties and powers to restore and enhance corporate image in the minds of the customer.

\section{Education and Training}

Education and training is the basic means for service enterprises to construct human resources and the knowledge base, education and training can also show the image of the enterprise about the sustainable development. Employees can also interpret the information from the education and training content of the enterprise development prospects. If the management personnel of enterprises mainly according to service needs determine the content of the education and training, help employees improve service skills, and improve service attitude, the employees will consider enterprises attach great importance to personal knowledge accumulation, they will actively participate in education and training, and strive to improve service ability. At the same time service enterprises for staff education and training can be divided into general skills and specific skills training, the latter can lock some employees and reduce the harm caused by turnover.

\section{Real Time Feedback and Reward for Employee Performance}

The complexity of service work determines the difficulty of assessing the performance of employees. Managers should assess the employee's work according to behavior or action including working enthusiasm, responsibility sense, cooperative spirit, service attitude, service orientation. Also managers should timely transmit massage to staff, help the employees to correct deficiencies in management. To reward excellent staff on the one hand can mobilize the enthusiasm of the staff to provide quality services, on the other hand, employees can feel the importance of enterprise service quality.

\section{Communicating with Employees}

Maintain communication channels between employees and enhance the communication effect is an important prerequisite to ensure the effect of psychological empowerment. Authorization is a way of working which requires timely information, understand each other's ideas and needs. Authorization at the same time should strengthen staffs' awareness about the significance of the work, enhance the status of employees in the enterprise strategy formulation and the implementation of the strategy, so that employees truly feel the value of their work. 


\section{Respect for the Autonomy of Employees}

Autonomous decision-making power is the core element of the psychological empowerment, and the promotion of employee psychological empowerment must respect the independent decision-making power of the employees. In the usual authorization management, the service enterprise should carry out the structural authorization. Managers in the daily activities prudent use of special power and emergency power, respect for the staff's enthusiasm and initiative, avoid the phenomenon of leapfrog command, otherwise intervention affairs will greatly affect the employees' confidence. Respect for employees' decision-making power does not mean indulgent, those does not have the corresponding conditions should be promptly recovered power.

\section{Establishment an Appropriate Internal Competition Mechanism to Increase the Sense of Urgency}

Appropriate internal competition mechanism is conducive to enhance employees' awareness of the value of work and the enthusiasm of learning, personal learning also can help to reservation of organizational knowledge. Internal competition can optimize the allocation of human resources and enhance the influence of high performance employees in the organization. But it should be noted that internal competition mechanism and staff urgent sense of the need should be controlled in a certain range, otherwise competitive climate will increase staffs' stress levels, hinder the interaction between knowledge and emotion communication, and influent the accumulation of tacit knowledge in service enterprise.

\section{Acknowledgement}

This research was supported by science and technology of Weifang tobacco institute (Research on the mechanism of improving the work performance of tobacco organizations under the guidance of the team)

\section{Reference:}

[1] Amabile, T. M., Motivating Creativity in Organizations: On Doing What You Love And Loving What You Do, California Management Review, 1997(40)

[2] Heskett, J.L., Sasser, W.E., Jr., \& Schlesinger, L.A.. The Service Profit Chain. New York: Free Press.1997.

[3] Hogan, J., Hogan, R., \& Busch, C.M.. How to measure service orientation. Journal of Applied Psychology,1984. 69.

[4] Jensen M B,Johnson B,Lorenz E,et al.Absorptive Capacity,Forms of Knowledge and Economic Development[R],paper presented at the Second Globelics Conference in Beijing,2004,October 16-20.

[5] Johnson, J. Linking Employee Perceptions to Customer Satisfaction. Personnel Psychology, 1996.49.

[6] Kline S J, N Rosenberg, An overview of innovation, Landau, R \& N Rosenberg (eds), The positive sum strategy: harnessing technology for economic growth, the National Academy Press, Washington D C, 1986.

[7] Kogut, Bruce and Udo Zander., Knowledge of the Firm, Combinative Capabilities, and the Replication of Technology, Management of Technology, 1992(3).

[8] Mayer R C, Davis J H, Schoorman F D. An Integrative Model of Organizational Trust. Academy of Management Review, 1995 (3) . 